\title{
STUDY OF NOISE LEVELS IN A NEONATAL INTENSIVE CARE UNIT
}

\author{
Chantal Laroche and Paula Fournier \\ Audiology and Speech-Language Pathology Program, University of Ottawa, 545 King Edward, P.O. Box 450, Stn A \\ Ottawa, Ontario, CANADA, KIN 6N5
}

\begin{abstract}
The integrated care approach has been a focal point of interest for the past few years. In this approach, noise is viewed as a compromising element in the normal development of newborns in neonatal intensive care units. The objective of this study was to develop a methodology that could evaluate the impact of a training program designed for nurses regarding existing noise levels within a neonatal intensive unit. This method entails measurements of noise levels and their sources. The method's development was based on a continuous evaluation of noise levels in a neonatal intensive care unit (NICU), using a computer (type 1 sound-level metre) before the nurses' training. In order to evaluate the impact of the nurses' training, noise level measurements obtained before training at described locations are to be repeated after training. LAeq, $1 \mathrm{sec}$, as well as audio samples were recorded throughout 8 work shifts. The project was conducted in an Ottawa regional hospital that specializes in the treatment of sick children. The average pre-training noise levels were $53 \mathrm{dBA}, 61 \mathrm{dBA}$ and $65 \mathrm{dBA}$, for the night, day, and evening shifts respectively. These levels largely exceed the maximum sound level of $40 \mathrm{dBA}$ recommended by the World Health Organization to avoid negative effects on sleep in hospitals. On the basis of this study, the training of nurses likely contributes to the reduction of noise levels in NICUs, but interventions concerning noise control are also necessary in order to ensure an acceptable sound environment for neonates requiring intensive care. (Project supported by the University of Ottawa)
\end{abstract}

\section{SOMMAIRE}

Au cours des dernières années, l'approche de soins intégrés a retenu l'attention. Entre autres, le bruit est considéré comme un élément qui peut compromettre le développement normal des nouveau-nés dans les unités de soins intensifs (NICU). L'objectif de cette étude était de développer une méthodologie qui permettrait d'évaluer éventuellement l'impact d'une formation des infirmières sur les niveaux de bruit prévalant dans les unités de soins intensifs. La méthode porte sur les mesures de bruit et leur source. L'élaboration de la méthode a été basée sur une évaluation continue des niveaux de bruit dans un NICU, avant la formation des infirmières, en utilisant un ordinateur (sonomètre, classe 1). Dans le but d'évaluer l'impact d'une formation des infirmières, les mesures des niveaux de bruit obtenus avant la formation devront être reprises après la formation. Des LAeq, $1 \mathrm{sec}$., ainsi que des échantillons audionumériques, ont été enregistrés lors de 8 périodes de travail. Le projet a été mené dans un hôpital pédiatrique de la région d'Ottawa. Les niveaux moyens de bruit pré-formation étaient de $53 \mathrm{dBA}, 61 \mathrm{dBA}$ et $65 \mathrm{dBA}$, pour la nuit, le jour et la soirée, respectivement. Ces niveaux dépassent largement le maximum de $40 \mathrm{dBA}$ recommandé par l'Organisation Mondiale de la Santé afin d'éviter les effets négatifs sur le sommeil. Sur la base de cette étude, il est prévu que la formation des infirmières devrait contribuer à réduire les niveaux de bruit, mais que des interventions de contrôle du brait à la source devront aussi être menées afin d'assurer une ambiance sonore acceptable pour les nouveau-nés qui requièrent des soins intensifs. (Projet financé par l'Université d'Ottawa) 


\section{INTRODUCTION}

In the past few years, efforts have been made to improve the physical and psychological environments of neonates within neonatal intensive care units (NICUs) (Als, Lawhon, Duffy, McAnulty, Gibes-Grossman \& Bicikman, 1994; Merenstein, 1994; Oehler, 1993; Tucker Blackburn \& VandenBerg, 1993). The impetus for this study came from caregivers based at Children Hospital of Eastern Ontario (CHEO), who were interested in applying and assessing the benefits of individualized care. In particular, they wished to measure the effect on physiological outcome and length of stay in the neonatal intensive care unit, of training nurses in this methodology. For this reason, it was crucial to assess the validity and reliability of the evaluation method, in order to assess the outcome of the training program. Above all, the caregivers at CHEO wanted to focus on the aspect of noise in NICUs.

\section{LITERATURE REVIEW}

The presence of noise in hospitals has become a major concern for both caregivers and researchers alike (Kurdahi Zahr \& Balian, 1995; Elander \& Hellström, 1995; Strauch et al., 1993; Topf 1992a \& b; Hodge \& Thompson, 1990; Topf \& Dillon, 1988; Webster \& Thompson, 1986; Topf, 1985; Aitken, 1982). In a document on community noise prepared for the World Health Organization, Berglund \& Lindvall (1995) recommended that the maximum sound level should not exceed $40 \mathrm{dBA}$ in order to maintain an acceptable environment for sleep in hospitals. The most important aspect is to ensure a low background noise level, such as $30 \mathrm{dBA}$. According to this internationally-used document, efforts should be made to reduce peak noise levels as well as the number of noise events before reducing the background equivalence level.

Anagnostakis, Petmezakis, Messaritakis \& Matsaniotis (1980) documented relatively high noise levels (48-56 dBA) in a neonatal intensive care unit. Although these levels are considered safe for adults, these researchers expressed their concerns regarding the physiological and psychological effects of these noise levels on premature neonates. Thomas (1989) commented that, given the immaturity of their central nervous systems, premature neonates cannot inhibit auditory stimulation. In fact, the functional integrity of the central nervous system is very precocious and, as a result, a slight tap or blow to the incubator, which can generate noise levels of $70 \mathrm{dBA}$ or $95 \mathrm{dBpeak}$, can trigger apnea or bradycardia. Many other negative effects have been associated with noise, including hypoxemia, intraventricular hemorrhage (Long et al., 1980), and reduced sensibility to auditory stimulation (Segall, 1972). Thomas (1989) also stated that noise levels tend to be higher with the complexity of the care/treatment. Consequently, the most vulnerable children were exposed to highest noise levels.

Tucker, Blackburn \& VandenBerg (1993) and Oehler (1993) also supported Thomas' findings by reporting the negative effects of the high noise levels in NICUs, insisting that neonates are at risk of neuro-developmental problems when the physical environment is not sufficiently controlled. Deficits, hyperexcitability and language difficulties are some of the problems that were encountered with the development of these children. Moreover, these authors brought attention to the fact that premature neonates spend several weeks to several months in an environment which is far different from that found inside the uterus. Finally, Thomas (1989) listed a number of potential solutions for noise reduction, such as the modification of warning alarms, less abrupt handling of the equipment (e.g. blows to the incubator, closing doors), the purchase of quieter equipment and the modification of caregivers' habits (e.g. limit conversations near the incubators).

A recent study by Als et al. (1994) demonstrated that the developmental approach, which aims to ensure a controlled environment (such as noise) for premature neonates, can provide tangible results. In order to demonstrate this, training based on the "Individualized developmental care for the very low-birth-weight preterm infant" model was given to a group of nurses responsible for the care of an experimental group of neonates. A control group received conventional care specific for this population. The researchers concluded that the neonates in the experimental group warranted less mechanical ventilation and oxygen than those in the control group. Furthermore, the children in the experimental group showed a reduced incidence rate of intraventricular or pneumothorax hemorrhaging, improved daily weight gain and younger age of discharge from the hospital.

During a recent conference, Canadian neonatalogists insisted on the need to study noise levels and characteristics in NICUs, in order to eventually assess the effect of noise reduction on neonates (Walker, 1995). Two studies have demonstrated that this can be done (Elander \& Hellström, 1995; Strauch et al., 1993). Both studies insisted on the collaborative efforts of all health care providers within the unit as well as the relative low cost and easy implementation of noise reduction methods. Among the most effective methods were: reducing verbal and radio noises, forwarding telephone calls to a more peripheral site, and coordinating the timing of laboratory procedures. However, there are limits associated with both studies cited. 
For example, few details are given about the measurement protocol (identification of noise sources, microphone placement, type of $\mathrm{dB}$ used). As a result, the focus of the present study is on the development of a rigorous method of noise level measurements.

\section{OBJECTIVES}

The objectives of this study included: (1) the development of a valid and reliable method of noise level measurements within a neonatal intensive care unit, in order to eventually evaluate the impact of the training program, (2) the documentation of the principal noise sources in terms of origin and levels, prior to the training of the caregivers, and (3) the drafting of recommendations in regards to the reduction of noise levels in NICUs (where the sources are the caregivers, the instruments and the environment).

\section{METHOD}

\subsection{Instrumentation}

The equipment used in this study included a Toshiba T5200 portable computer equipped with $01 \mathrm{~dB}$ software $(\mathrm{dB}$ Trig: equivalent to a Type 1 integrating sound level meter (CEI 804,1985), a 1/2" microphone (Cirrus) with windscreen, and a $1 \mathrm{kHz}-94 \mathrm{~dB}$ calibrator.

\subsection{General Procedure}

Since one of the objectives of this study was to eventually analyze noise level differences before and after the nurses' training, the noise measurement procedure had to be very strict and representative of the noise encountered on a typical day in the NICU. In order to do so, different methods were consulted such as the standards related to noise measurements (e.g. CSA Standards Z107.56, 1994), and the methods proposed for the work environment (Laroche, 1989) and other environments such as nursery schools (Truchon-Gagnon \& Hétu, 1988). The methods for noise level measurements intended for nursery schools were favored in this case, since they can account for a multitude of noise sources, and the very variable noise characteristics encountered in NICUs (Truchon-Gagnon \& Hétu, 1988). In fact, these methods combine two complementary approaches. The first is a quantitative approach which aims to evaluate noise levels, by means of a sound level meter, at different times of the day and for different noise sources. The second is a qualitative approach which aims to obtain the maximum amount of information regarding noise sources and their origins, by means of an observation chart (Bélair, Lafleur, et Leroux, 1986).
Quantitative and qualitative noise samples were taken during eight periods of approximately six hours each, including three day shifts (7am to $3 \mathrm{pm}$ ), three evenings shifts (3pm to $11 \mathrm{pm}$ ) and two nights shifts (11pm to $7 \mathrm{am}$ ). The use of computerized measurement equipment $(01 \mathrm{~dB}$ software on Toshiba T5200) was chosen in order to collect as much data as possible at one site. Moreover, the computerized measurement system permitted the recording of digitized sound samples directly onto a hard-drive. These audionumeric recordings consisted of a few seconds each and were obtained approximately every five minutes. These recordings allowed a comparison with the measured sound levels and facilitated the recognition of noise sources identified by means of an observation chart. This procedure also served as a validation tool for the research assistant's visual and auditory observations.

The noise-level measurements did not, at any time, interfere with the work of the nursing staff. The microphone was positioned 1 meter from the neonate's head. The microphone positions were chosen to allow for a more accurate characterization of the noise levels throughout space. The exact microphone placement will be repeated in each room after the training session, in order to correctly recreate the testing scenario. The data collection of the noise-level measurements after the nurses' training, will be the object of another project.

A major concern during the data-collection procedure was to ensure that no bias existed while the measurements were being taken. The nursing staff, clinicians and parents were all informed that noise measurements were being taken during the eight week period and that the audio-recorded data collected would remain confidential. Also, in order to ensure the representativeness of the noise environment, the nursing staff was consulted daily at the end of each measurement period. Had the nurses stated that the measurements were not representative, we would have eliminated the data during those shifts.

\subsection{Specific procedures for noise level measurements}

The noise level measurements were performed according to the method prescribed in CSA Standards Z107.56 (1994). In all instances, the computerized sound level meter $(01 \mathrm{~dB}$ software) was calibrated in situ by the use of an acoustic calibrator (1 kHz, $94 \mathrm{~dB}$ ), prior to and following each measurement session. If, at the end of the measurement, the calibration had shifted more than $0.5 \mathrm{~dB}$, the data would have been discarded. Also, the microphone was positioned 1 meter from the neonate's head. For each of the microphone placements, the following data were collected: (a) description of the activities in the room's surroundings (by means of an observation chart), (b) duration, date and 
time of measurement, ( c) $\mathrm{L}_{\text {Aeq, 1sec }}$ (A-weighted equivalent continuous sound pressure level for each 1 second period), (d) percentage of the average time devoted to each activity, and (e) microphone placement.

\subsection{Description of the neonatal intensive care unit at CHEO}

The NICU at CHEO consists of three rooms and a reception area. Figure 1 shows a diagram of room \#3. The noise measurements were performed in rooms \#2 and \#3 since room \#1 was rarely used. Each room can be occupied by up to eight infants, whether in cribs, bassinets, incubators or beds with overhead heaters. In rooms $\# 2$ and $\# 3$, both side walls had windows from mid-wall to ceiling. The walls in both rooms were covered with gyps, the floors were covered with ceramic tiles and ceilings were surfaced with acoustic tiles. A rectangular melamine covered work station containing two computers and a sink was located in the centers of each of the rooms. A second sink was located at the entrance door, along the front wall. A telephone and an intercom system speaker were placed beside the door. The metal-covered ventilation system was located on the back wall on the right hand side. Typically, three to four infants were placed along the two side walls, to a maximum of eight to a room.

\section{DATA ANALYSIS}

\subsection{Analysis of sound level measurements}

The data were analyzed according to the qualitative and quantitative approaches. The observations obtained by means of the chart were paired with the sound levels measured by the computerized measurement system. The noise levels were then averaged for each typical situation in the NICU, as well as for each half hour, one hour, day, evening and night periods. The data are presented in tables to facilitate their comparison, as well as their comparison to the post-training measurements. The data presented in the Table 1 are divided on the basis of the time of day of the work shift. As a result, there are three sets of data (day, evening and night) displaying the sound level measurements obtained on those various day, evening and night shifts. Also, the ceiling $\left(\mathrm{L}_{5}\right)$ and floor $\left(\mathrm{L}_{95}\right)$ noise levels are displayed in Table 1 . The $L_{5}$ or ceiling noise levels indicate that only $5 \%$ of all noise levels would be superior to this given value. On the other hand, the $\mathrm{L}_{95}$ or floor noise levels indicate that $95 \%$ of all noise levels would be superior to this given value.

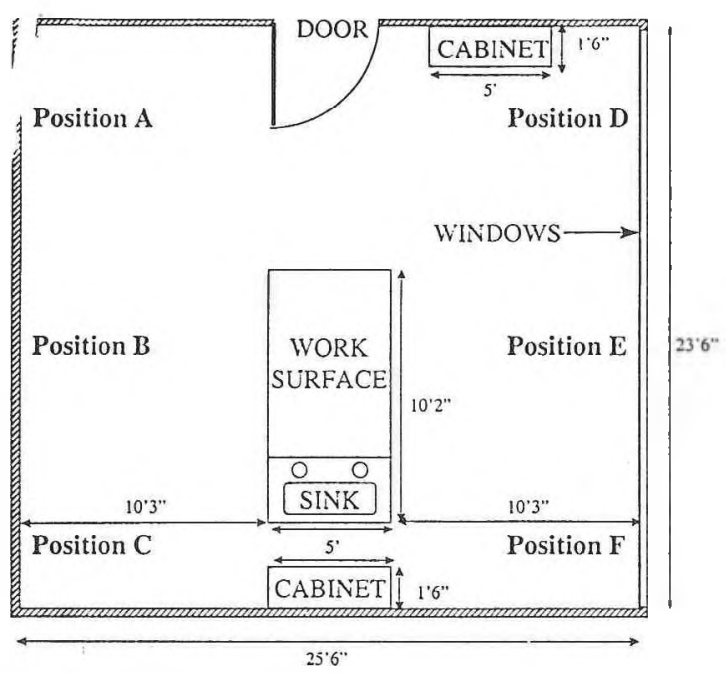

Figure 1. Diagram of room \#3

\subsection{Determination of the occurrence of presentation of various noise sources}

The total number of occurrences for each of the identified noise sources was listed for each of the measurement periods. This total was then divided by the duration of the measurement period, in hours, which produced a number of presentations per hour. As for the samples of the infants' speech and cries, the duration and occurrence of these presentations were combined and are therefore presented as a percentage of time.

\section{RESULTS AND DISCUSSION}

\subsection{Sound level measurements}

An example of the variation of sound levels obtained in the course of the first day shift are presented in Figure 2. Although it may be interesting to study the variation in sound levels from one day to another for the same time period, it may also be useful to measure the sound level variations within a 24 hour period. Table 1 gives minimum and maximum overall L5 and L95 values for each time period.

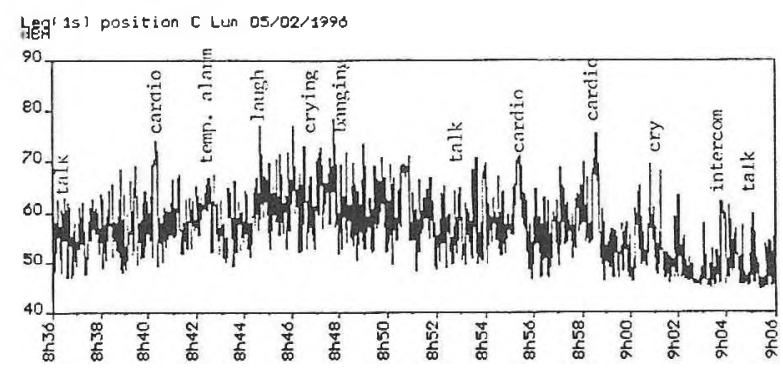

Figure 2. Example of the sound pressure level's evolution (dBA) as a function of time. Different sound sources are identified on the figure. 


\begin{tabular}{|c|c|c|c|}
\hline & \multicolumn{3}{|c|}{ Day shifts } \\
\hline & Overall & $\mathbf{L}_{95}$ & $\mathbf{L}_{5}$ \\
\hline Sound levels & $59-62 \mathrm{dBA}$ & $48-51 \mathrm{dBA}$ & $65-67 \mathrm{dBA}$ \\
\hline \multirow[t]{3}{*}{ AVERAGE } & $61 \mathrm{dBA}$ & $50 \mathrm{dBA}$ & $66 \mathrm{dBA}$ \\
\hline & \multicolumn{3}{|c|}{ Evening shifts } \\
\hline & Overall & $\mathrm{L}_{95}$ & $\mathbf{L}_{5}$ \\
\hline Sound levels & $61-65 \mathrm{dBA}$ & $45-61 \mathrm{dBA}$ & $65-68 \mathrm{dBA}$ \\
\hline \multirow[t]{3}{*}{ AVERAGE } & $63 \mathrm{dBA}$ & $57 \mathrm{dBA}$ & $67 \mathrm{dBA}$ \\
\hline & \multicolumn{3}{|c|}{ Night shifts } \\
\hline & Overall & $\mathbf{L}_{95}$ & $\mathbf{L}_{5}$ \\
\hline Sound levels & $48-55 \mathrm{dBA}$ & $39-47 \mathrm{dBA}$ & $54-61 \mathrm{dBA}$ \\
\hline \multirow[t]{2}{*}{ AVERAGE } & $53 \mathrm{dBA}$ & $45 \mathrm{dBA}$ & $59 \mathrm{dBA}$ \\
\hline & \multicolumn{3}{|c|}{24 hour period } \\
\hline $\begin{array}{l}\text { OVERALL } \\
\text { AVERAGE }\end{array}$ & $61 \mathrm{dBA}$ & $53 \mathrm{dBA}$ & $65 \mathrm{dBA}$ \\
\hline
\end{tabular}

Table 1. Minimum and maximum overall sound levels, floor sound levels (L5) and ceiling sound levels (L95) for each shift period and a 24 hour period.

\subsection{Relationship between sound levels and the period of the day}

The average overall sound level for a 24 hour period obtained in this study was $61 \mathrm{dBA}$. During the day shifts, the overall sound levels increased due to medical and radiology rounds. Radiology work was generally completed in the early afternoon, between $12: 00 \mathrm{pm}$ to $2: 00 \mathrm{pm}$, which may have caused floor noise and therefore, overall sound levels, to increase. Moreover, the presence of infant cries, conversations, and the set-off of alarms contributed to these elevated sound levels, which appear to be more prevalent in the morning, from 8:30am to 9:30am.

Fluctuating sound levels during the evening were usually due to excessive conversation (e.g. nursing staff shift change, medical intervention) or to infant cries, which often led to more frequent set-off of alarms. Also, the noise levels were highly affected by the equipment in the NICU. As for the night period, infant cries and warning alarms caused the many sound level variations.

\subsection{Overall, floor noise and maximum sound level}

As indicated in Table 1, the average sound level was highest during the evening shifts (63 dBA) and lowest during the night shifts $(53 \mathrm{dBA})$. The average sound level measured in the 24 hour period was $61 \mathrm{dBA}$. This particular sound level is higher than the recommended sound levels in a private residence, which are $35 \mathrm{dBA}$ during the night and $45 \mathrm{dBA}$ in the daytime, and in hospitals, which are $30 \mathrm{dBA}$ for the background noise and
$40 \mathrm{dBA}$ for the maximum noise level (Berglund \& Lindvall, 1995).

The floor noise levels were highest in the evening (57 dBA) and lowest during the night shifts ( $45 \mathrm{dBA})$. Again, these noise level exceeded the recommended levels established by the WHO (Berglund \& Lindvall, 1995). Furthermore, the average floor noise level for the 24 hour period is $53 \mathrm{dBA}$, which once again exceeds the recommended noise levels established by the WHO (Berglund \& Lindvall, 1995).

There was no marked difference in maximum sound level measurements $\left(L_{5}\right)$ between the day and evening shifts. However, the maximum sound levels $\left(L_{5}\right)$ obtained during the night shift were lower than those obtained during the day and evening shifts. Finally, as demonstrated in Table 1 , the noise level measurements obtained during the evening shifts were higher than those obtained during the day and night shifts.

\subsection{Presentation of sound levels and occurrence of various common noise sources}

Tables 2 and 3 focus on sound level and the occurrence of individual noise sources, in order to determine their level of contribution to the overall sound levels. As indicated in Table 2, the highest average sound level among the warning alarms was the IV pump alarm (68 $\mathrm{dBA})$. In regards to human vocalizations, laughter had the highest average sound level ( $73 \mathrm{dBA})$. Finally, the act of "putting down the crib's wall" (75 dBA) produced the highest average sound level overall, as well as the highest level within the object noise sources.

As indicated in Table 3, the cardio monitor alarm was the most frequent among the warning alarms ( 5 times per hour). Among human vocalizations, conversation occurred most often ( $38 \%$ of the time). As for object noise sources, sink and towel ripping noises were the most frequent ( 4.7 times per hour, each).

\section{GENERAL DISCUSSION}

Given the fact that the primary objective of this study was to develop a valid and reliable method of noise measurement within the NICU as well as the eventual evaluation of the impact of a specified training program, it was imperative throughout this study to ensure the method's replicability. As described in the methodology, the various methods and protocols utilized throughout the data collection for this study were chosen carefully and executed rigorously, to ensure their reproducibility in a post-training study. Recommendations are formulated based on these data. 


\begin{tabular}{||l|l|l|}
\hline $\begin{array}{c}\text { General noise } \\
\text { source }\end{array}$ & \multicolumn{1}{|c|}{ Specific noise source } & \multicolumn{1}{|c|}{$\begin{array}{c}\text { Average } \\
\text { sound level * }\end{array}$} \\
\hline - warning & - IV pump alarm & $68 \mathrm{dBA}(60-71)$ \\
alarms & - cardio monitor alarm & $66 \mathrm{dBA}(56-69)$ \\
& - feeder pump alarm & $65 \mathrm{dBA}(59-70)$ \\
& - overhead heater alarm & $64 \mathrm{dBA}(62-67)$ \\
& - oxygen saturation & $63 \mathrm{dBA}(56-66)$ \\
& monitor alarm & \\
\hline -human & - laughing & $73 \mathrm{dBA}(56-80)$ \\
& - baby cries & $69 \mathrm{dBA}(58-74)$ \\
& - coughing & $69 \mathrm{dBA}(62-73)$ \\
& - conversation & $64 \mathrm{dBA}(52-69)$ \\
\hline - object noises & - putting down crib railing & $75 \mathrm{dBA}(71-77)$ \\
& - cupboard door bang & $71 \mathrm{dBA}(58-76)$ \\
& - object dropped & $70 \mathrm{dBA}(53-73)$ \\
& - poll or crib rolled & $69 \mathrm{dBA}(52-75)$ \\
& - radio & $69 \mathrm{dBA}(68-70)$ \\
& - binder & $68 \mathrm{dBA}(54-71)$ \\
& - towel ripped & $67 \mathrm{dBA}(56-72)$ \\
& - radiology & $67 \mathrm{dBA}(64-69)$ \\
& - supply cart rolled & $66 \mathrm{dBA}(54-70)$ \\
& - telephone ring & $65 \mathrm{~dB}$ \\
& - floor washing, chair rolled & $64 \mathrm{dBA}(52-68)$ \\
& - oscillator, intercom, sink & $63 \mathrm{dBA}(53-67)$ \\
& - sterile pack snapped open & $60 \mathrm{dBA}(54-62)$ \\
& - paper shuffled & $58 \mathrm{dBA}(51-61)$ \\
& - musical mobile & $54 \mathrm{dBA}(53-54)$ \\
& - ventilator & $48 \mathrm{dBA}$ \\
\hline
\end{tabular}

*(minimum and maximum values $-\mathrm{dBA}$ )

Table 2. Various sound sources, in descending order of sound levels

\begin{tabular}{|l|l|l|}
\hline $\begin{array}{l}\text { General } \\
\text { noise source }\end{array}$ & Specific noise source & Occurrence \\
\hline - warning & - cardio monitor alarm & 5 min. per hour \\
alarms & - syringe pump alarm & 2 min. per hour \\
& - overhead heater alarm & 1.5 min. per hour \\
& - oxygen monitor alarm & 1 min. per hour \\
& - IV pump alarm & 0.6 min. per hour \\
\hline - human & - conversation & $38 \%$ of the time* \\
vocalizations & - crying & $15 \%$ of the time* \\
& - coughing & 0.5 times per hour \\
& - laughing & 0.2 times per hour \\
\hline - object noises & - sink & 4.7 times per hour \\
& - towel ripped & 4.8 times per hour \\
& - cupboard banged & 1.4 times per hour \\
& - binder & 0.6 times per hour \\
& - intercom & 0.7 times per hour \\
& - object dropped & 0.5 times per hour \\
\hline
\end{tabular}

* frequency of occurrence for conversation and crying is presented as a percentage value because these are continuous, rather than instantaneous

Table 3. Various sound sources in descending order of presentation occurrence

\subsection{Comparison of sound levels with other studies}

The average sound levels were higher by as much as $10 \mathrm{~dB}$ in comparison with those obtained in previous studies. These differences could be explained in part by the fact that the methods and protocols in other studies were not identical to those adopted throughout this study. However, these differences are more likely due to the fact that the noise sources at CHEO emit higher sound levels. As previously mentioned, the average overall sound level obtained in this study for a 24 hour period was $61 \mathrm{dBA}$. Nagorski Saunders (1995) obtained an overall sound level of $58 \mathrm{dBA}$. Anagnostakis et al. (1980) measured an overall sound level of $51 \mathrm{dBA}$, which is much lower than that obtained in this study. Furthermore, based on physics principles, this $10 \mathrm{dBA}$ difference represents ten times more acoustic energy in the NICU at CHEO.

\subsection{Occurrences and sound levels of the noise sources}

Based on the observations and measurements obtained in this study, conversation, infant cries and the set-off of alarms represent the primary noise sources in the NICU at CHEO. The average sound level of conversation obtained in this study was $64 \mathrm{dBA}$, a level comparable to that reported by Thomas (1989) of 58-64 dB. Furthermore, over the course of this study conversation occurred more often than all other noise sources identified in the NICU. It was present $38 \%$ of the time, whereas infant cries were only present $15 \%$ of the time. However, these cries were measured at relatively higher sound levels than conversation (69 dBA vs. $64 \mathrm{dBA}$ ), making them an important contributor to the overall sound level in the NICU. As a result, conversation and infant cries, which can be continuous noise, contributed greatly to the overall noise level. The floor noise level could have been influenced by the presence of these noise sources. Furthermore, the floor noise level depended on the equipment functioning in the room.

Some warning alarms (10 per hour), "banging" noises (cupboard doors, binder, carts, etc.), a person coughing and other noise sources (telephone ringing, sink, ripping of a paper towel) were identified as being intermittent-short duration noises, emitting sound levels of over $60 \mathrm{dBA}$. In fact, as measured in this study, the average sound levels of the IV pump alarm and of the sink were $68 \mathrm{dBA}$ and 62 dBA, respectively. Similarly, Thomas (1989) reported an average sound level of $56 \mathrm{~dB}$ for the IV pump alarm and 66 $\mathrm{dB}$ for the sink. Although many of these noises are of short duration, it is important to note that they may still cause distress for the infants, as impact noises are more disturbing 
than continuous noises. More specifically, sound level measurements for impact noises produced by both the $\mathrm{O} 2$ saturation monitor alarm and the Drager SC-8000 incubator temperature alarm were $62 \mathrm{dBA}$ and $73 \mathrm{dBA}$ respectively, exceeding the $60 \mathrm{~dB}$ noise level sufficient to increase anxiety, as reported by Standing and Stace (1980).

Finally, the World Health Organization (1980) specifies that noise levels higher than $30 \mathrm{dBA}$ Leq may cause frequent arousals during sleep in hospitals. The floor noise levels in the NICU at CHEO largely exceed this $30 \mathrm{dBA}$ value.

\subsection{Physiological measures to consider in pre- and post-noise reduction}

Very few studies used physiological measures to demonstrate the outcome of noise reduction on neonates in NICUs (Als et al., 1994; Kurdahi Zahr \& Balian, 1995). In Kurdahi Zahr \& Balian's study, three physiological measures: infant's heart rate, respiratory rate (RR) and oxygen saturation ( $\mathrm{SaO} 2)$ were used. Many variables were studied in Als et al. (1994) experiment but they were based on medical outcome variables like average daily weight gain and number of days on oxygen. It would be interesting to consider these types of physiological and medical variables in a pre- and post- training study, because it would give stronger support to noise reduction than simply considering infants' states (like quality of sleep), as it as been done in other studies (Strauch et al., 1993).

\section{RECOMMENDATIONS}

The following paragraphs present recommendations regarding warning alarms, human vocalizations and objectrelated noises.

\subsection{Warning alarms}

Several different alarms were identified in the NICU. These alarms generally produced abrupt, intermittent, and relatively high-pitched signals louder than $60 \mathrm{dBA}$. This level is able to startle a child and neighboring infants, as well as to cause annoyance to the nursing staff. Furthermore, as observed in the NICU, each child was usually monitored by at least one of these alarms. As the state of health of the newborn decreased, the number and frequency of alarms increased. In order to reduce their duration and occurrence, the NICU staff would need to respond more rapidly to the alarms and their causes. In addition, the alarms must be perceived by the NICU staff through the continuous ambient noise, which includes conversation and equipment. As a result, the reduction of background noise is also a priority. Once the background noise is lowered, reducing the sound levels of the various alarms would be essential, and would require the efforts of manufacturers.

These recommendations are similar to those proposed in other studies examining noise and the audibility and identification of various alarms in hospitals. In fact, Cropp, Woods, Raney \& Bredle (1994), as well as Montahan, Hétu \& Tansley (1993), concluded that the number and frequency of alarms that were set-off in the various intensive care units were too abundant for the staff to correctly discern them from one another. As a result, both these studies encouraged the reduction of noise in these ICUs by limiting the number of alarms, by finding alternatives to auditory alarm signals, by designing better units and by reducing the background noise levels. Another study by Nagorski Saunders (1995) concluded that shielding the top and sides of the incubators with quilted coverings was an effective method of in-situ noise reduction.

\subsection{Human vocalizations}

Another recommendation would be to organize an awareness campaign focused on the negative effects of noise on patients and staff which would emphasize noise reduction. As demonstrated in the study by Benini, Magnavita, Lago, Arslan \& Pisan (1996), it is important to train NICU caregivers about the effects of noise, especially human vocalizations, and about the significance of noise reduction on newborns. In order to do so, a committee could be formed with the reduction of conversations near the resting infants as its first goal. Ideally, posters would be displayed reminding staff and visitors that silence is an essential condition for sleep. Moreover, end of work shift nursing reports should not, as much as possible, be held in proximity to the infants. Also, the number of physicians and students near the newborns during medical rounds should be reduced or these rounds should not be held near resting infants. Finally, if possible, the parents could bring their child into a separate visitor's room, in order to give him or her reprieve from environmental noises, such as other infant cries, conversation and alarms.

\subsection{Object-related noises}

Numerous recommendations are presented in regards to object-related noise productions. Table 4 presents examples of recommendations. 


\begin{tabular}{|l|l|}
\hline Noise sources & Noise reduction recommendations \\
\hline $\begin{array}{l}\text { - stainless steel trays, } \\
\text { pans and sinks }\end{array}$ & $\begin{array}{l}\text { - cover with absorbent material, such } \\
\text { as liquid rubber }\end{array}$ \\
\hline - carts, chairs, and cribs & $\begin{array}{l}\text { - fit with larger wheels, cover with } \\
\text { absorbent material, regular } \\
\text { maintenance (lubrication of mobile } \\
\text { parts) }\end{array}$ \\
\hline - cupboard doors & - absorbent pads \\
\hline - ceramic-tile floors & - cover with absorbent material \\
\hline $\begin{array}{l}\text { - binders (loud clicking } \\
\text { sounds) }\end{array}$ & $\begin{array}{l}\text { - replace with those equipped with } \\
\text { sliding-closing apparatus }\end{array}$ \\
\hline - towel dispenser & $\begin{array}{l}\text { - replace with those that do not } \\
\text { require "ripping" }\end{array}$ \\
\hline $\begin{array}{l}\text {-sterile packs } \\
\text { - open with scissors (instead of } \\
\text { tearing) }\end{array}$ \\
\hline $\begin{array}{l}\text { - housekeeping and other } \\
\text { outside noise }\end{array}$ & $\begin{array}{l}\text { - keep NICU door closed as much as } \\
\text { possible }\end{array}$ \\
\hline $\begin{array}{l}\text { - noise within the NICU } \\
\text { (bathing the infants, } \\
\text { procedures performed on } \\
\text { the infants, washing } \\
\text { hands, medical rounds, } \\
\text { etc.) }\end{array}$ & $\begin{array}{l}\text { - utilize the center room as an } \\
\text { 'activity station" }\end{array}$ \\
\hline $\begin{array}{l}\text { - reverberation within the } \\
\text { NICU }\end{array}$ & $\begin{array}{l}\text {-curtain the windows and acoustic } \\
\text { paneling on ceiling }\end{array}$ \\
\hline
\end{tabular}

Table 4. Recommendations for object-related noises

\section{CONCLUSIONS}

The measurement method has been validated throughout this study. Ultimately, the various measurements will be repeated in a post-training session, in order to evaluate whether or not, based on this study's recommendations and the training program, the noise levels in the NICU have significantly decreased.

\section{REFERENCES}

Aitken, R.J. 1982. Quantitative noise analysis in a modern hospital. Archives of Environmental Health 37(6): 361-364.

Als, H., Lawhon, G., Duffy, F.H., McAnulty, G.B., GibesGrossman, R. and Bicikman, J.G. 1994. Individualized developmental care for the very low-birth-weight preterm infant. JAMA 272(11): 853-858.

Anagnostakis, D., Petmezakis, J. Messaritakis, J. and Matsaniotis, N. 1980. Noise pollution in neonatal units: A potential health hazard. Acta Paediatr Scand 69: 771-773.

Bélair, M., Lafleur, G. and Leroux, T. 1986. Rapport de l'étude exploratoire de bruit entreprise au centre hospitalier de Verdun. Université de Montréal, École d'orthophonie et d'audiologie, Mai 1986.
Benini, F., Magnavita, M.S., Lago, P., Arslan, E. and Pisan, P. 1996. Evaluation of noise in the neonatal intensive care unit. American Journal of Perinatology 13 (1): 37-41.

Berglund, B. and Lindvall, T. 1995. Community Noise. Archives of the Center for Sensory Research 2, Document prepared for the World Health Organization: $195 \mathrm{p}$.

CEI 804 (1985). Sonomètres intégrateurs. Commission Électrotechnique Internationale.

Cropp, A., Woods, L., Raney, A. and Bredle, D. 1994. Name that Tone - The Proliferation of Alarms in the Intensive Care Unit. CHEST 105 (4): 1217-1220.

C.S.A. Standard Z107.56 1994. Méthode de mesure de l'exposition au bruit en milieu de travail. Rexdale: Canadian Standards Association.

Elander, G. and Hellström, G. 1995. Reduction of noise levels in intensive care units for infants: Evaluation of an intervention program. Heart \& Lung 24: 376-379.

Hodge, B. and Thompson, J.F. 1990. Noise pollution in the operating theatre. The Lancet 335: 891-894.

Kurdahi Zahr, L. and Balian, S. 1995. Response of premature infants to routine nursing interventions and noise in the NICU. Nursing Research 44: 179-185.

Laroche, C. 1989. La mesure de l'exposition au bruit: la loi au détriment de la santé?. Travail et Santé 5(3): 49-52.

Long, J.G., Lucey, J.F. and Phillips, A.G.S. 1980. Noise and hypoxemia in the intensive care nursery. Pediatrics 65: 143-145.

Merenstein, G.B. 1994. Invidualived Developmental Care. An Emerging New Standard for Neonatal Intensive Care Units? JAMA 272(11): 890-891.

Montahan, K., Hétu, R. and Tansley, B. 1993. Audibility and identification of auditory alarms in the operating room and intensive care unit. Ergonomics 36 (10): 1159-1176.

Nagorski Saunders, A. 1995. Incubator noise: A method to decrease decibels. Pediatric Nursing 21: 265-268.

Oehler, J.M. 1993. Developmental care of low birth weight infants. Advances in clinical nursing research 29: 289-301.

Segall, M.E. 1972. Cardiac responsivity to auditory stimulation in premature infants. Nurs. Res. 21: 15-19.

Standing, L. and Stace, G. 1980. The Effects of Environmental Noise on Anxiety Level. The Journal of General Psychology 103: 263-272. 
Strauch, C., Brandt, S. and Edwards-Beckett, J. 1993. Implementation of quiet hour: effect on noise levels and infant sleep states. Neonatal network 12: 31-35.

Thomas, K.A. 1989. How the NICU environment sounds to a preterm infant. MCN 14: 249-251.

Topf, M. 1985. Personal end environment predictors of patient disturbance due to hospital noise. Journal of applied psychology 70(1): $22-28$

Topf, M. 1992a. Effect of personal control over hospital noise on sleep. Research in Nursing \& Health 15: 19-28.

Topf, M. 1992b. Stress effects of personal control over hospital noise. Behavioral Medicine 18: 84-94.

Topf, M. and Dillon, E. 1988. Noise-induced stress as a predictor of burnout in critical care nurses. Heart \& Lung 17(5): 567-574.

Truchon-Gagnon, C. and Hétu, R. 1988. Noise in day-care centers for children. Noise Control Engineering Journal 30(2): 57-64.

Tucker Blackburn, S. and VandenBerg, K.A. 1993. Assessment and management of neonatal neurobehavioral development. In Comprehensive neonatal nursing: a physiologic perspective, Kenser, C., Brueggemeyer, A., Gurgeron, L. (eds). W.B. Saunders, 1094-1130.

Walker, R. 1995. Ross Conference on the Neonatal Environment Summary, personal communication.

Webster, R.A. and Thompson, D.R. 1986. Sleep in hospital. Journal of Advanced Nursing 11: 447-457.

\section{ACKNOWLEDGMENTS}

The authors would like to thank Elisabeth Churcher, Jocelyne Lawrence, Dr Robin Walker and all the nurses of the Neonatal Intensive Care Unit (NICU) of the Children Hospital of Eastern Ontario (CHEO) for their support and collaboration. The authors would also like to acknowledge Sophie Heley and Renée Lefrançois for their help in the English revision of this report and two anonymous reviewers for their helpful comments. Furthermore, this project was completed with grants from University of Ottawa's Faculty of Health Sciences and the Office of the Vice-Rector (Academic) under the Policy on the Pro-active Recruitment of Women Professors.

EDITORIAL BOARD / COMITÉ EDITORIAL

ARCHITECTURAL ACOUSTICS:

ACOUSTIQUE ARCHITECTURALE:

ENGINEERING ACOUSTICS / NOISE CONTROL: GÉNIE ACOUSTIQUE / CONTROLE DU BRUIT:

PHYSICAL ACOUSTICS / ULTRASOUND: ACOUSTIQUE PHYSIQUE / ULTRASONS:

PSYCHOLOGICAL ACOUSTICS:

PSYCHO-ACOUSTIQUE:

PhYSIOLOGICAL ACOUSTICS:

PHYSIO-ACOUSTIQUE:

SHOCK / VIBRATION:

CHOCS / VIBRATIONS:

HeARING ScIENCES:

AUDITION:

SPEECH SCIENCES:

PAROLE:

UNDERWATER ACOUSTICS:

ACOUSTIQUE SOUS-MARINE:

Signal Processing / Numerical Methods: Traitment des SignauX/ METHOdes NumeriQues:

CONSULTING:

CONSULTATION:

ADVISOR:

MEMBER CONSEILLER:
Gilbert Soulodre

Frédéric Laville

Michael Stinson

Annabel Cohen

Robert Harrison

Osama Al-Hunaidi

Kathy Pichora-Fuller

Linda Polka

Garry Heard

Ken Fyfe

Bill Gastmeier

Sid-Ali Meslioui
Carleton University

(613) $998-2765$

Ecole technologie supérieure

National Research Council

(613) 993-3729

University of P. E. I.

(902) 628-4331

Hospital for Sick Children

(416) 813-6535

National Research Council

(613) $993-9720$

University of British Columbia

(604) $822-4716$

McGill University

(514) 398-4137

D. R. E. A.

(902) 426-3100

University of Alberta

(403) 492-7031

HGC Engineering

(905) 826-4044

Aiolos Engineering
(416) 674-3017 


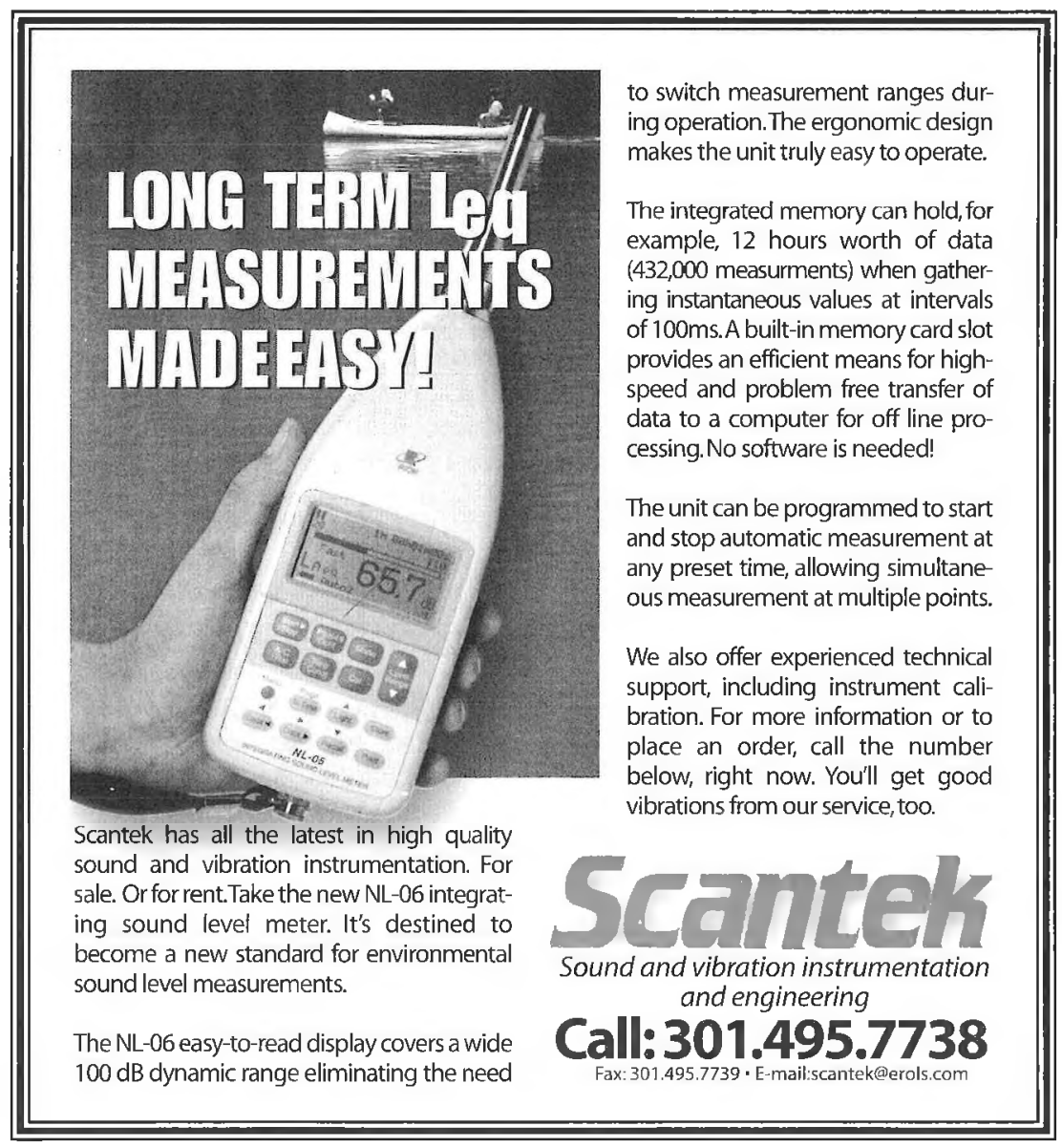

\section{CASELLA CEL INSTRUMENTS!}

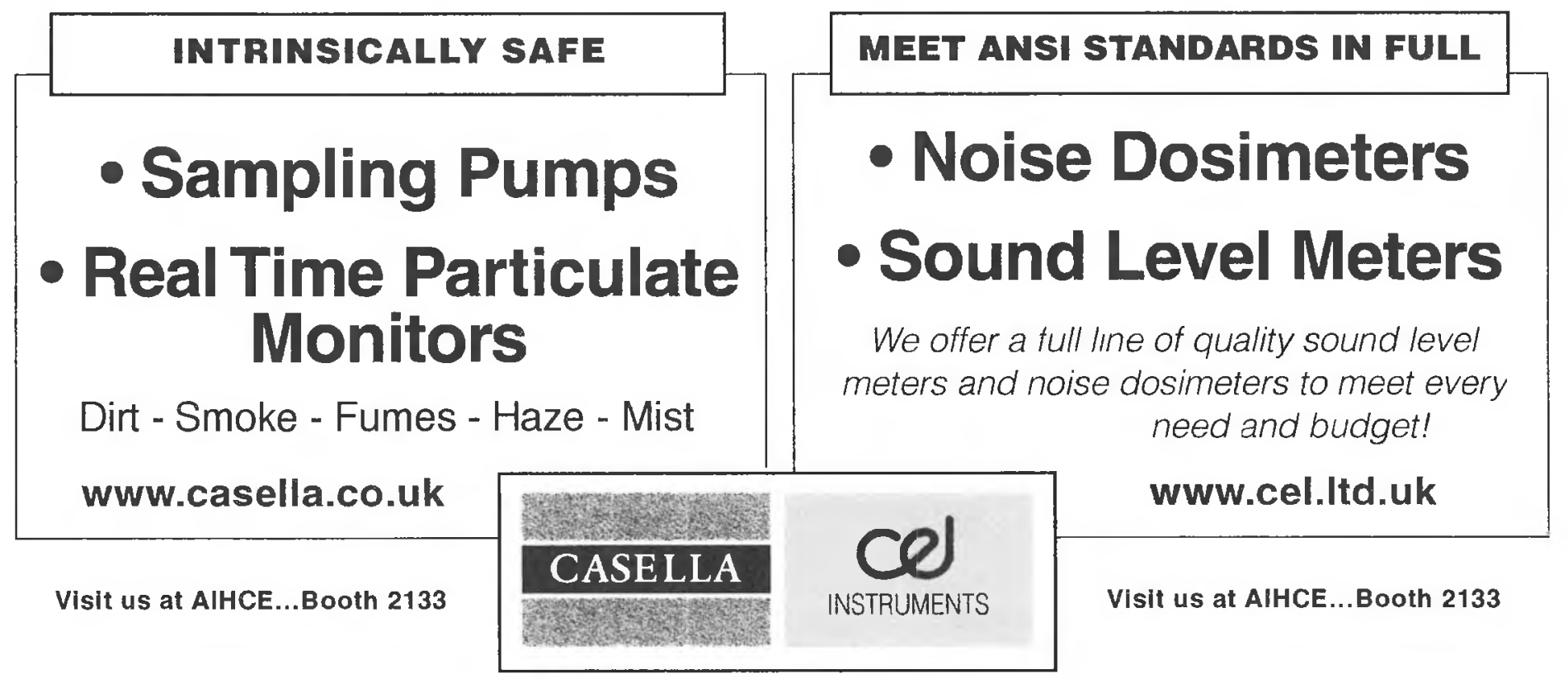

DIscover the many advantages that CASELLA CEL products have to offer!

\section{Call 800-366-2966 or write today!}

1 Westchester Drive, Milford, NH 03055, Fax: 603-672-7382 


\section{INSTRUCTIONS TO AUTHORS FOR THE PREPARATION OF MANUSCRIPTS}

Submissions: The original manuscript and two copies should be sent to the Editor-in-Chief.

General Presentation: Papers should be submitted in camera-ready format. Paper size $8.5^{\prime \prime} \times 11$ ". If you have access to a word processor, copy as closely as possible the format of the articles in Canadian Acoustics 18(4) 1990. All text in Times-Roman $10 \mathrm{pt}$ font, with single (12 pt) spacing. Main body of text in two columns separated by 0.25 ". One line space between paragraphs.

Margins: Top - title page: 1.25"; other pages, 0.75"; bottom, $1 "$ minimum; sides, 0.75 ".

Title: Bold, 14 pt with 14 pt spacing, upper case, centered.

Authors/addresses: Names and full mailing addresses, $10 \mathrm{pt}$ with single (12 pt) spacing, upper and lower case, centered. Names in bold text.

Abstracts: English and French versions. Headings, $12 \mathrm{pt}$ bold, upper case, centered. Indent text 0.5 " on both sides.

Headings: Headings to be in 12 pt bold, Times-Roman font. Number at the left margin and indent text 0.5 ". Main headings, numbered as $1,2,3, \ldots$ to be in upper case. Sub-headings numbered as $1.1,1.2,1.3, \ldots$ in upper and lower case. Subsub-headings not numbered, in upper and lower case, underlined.

Equations: Minimize. Place in text if short. Numbered.

Figures/Tables: Keep small. Insert in text at top or bottom of page. Name as "Figure 1, 2, ..." Caption in 9 pt with single (12 pt) spacing. Leave 0.5 " between text.

Photographs: Submit original glossy, black and white photograph.

References: Cite in text and list at end in any consistent format, 9 pt with single (12 pt) spacing.

Page numbers: In light pencil at the bottom of each page.

Reprints: Can be ordered at time of acceptance of paper.

\section{DIRECTIVES A L'INTENTION DES AUTEURS PREPARATION DES MANUSCRITS}

Soumissions: Le manuscrit original ainsi que deux copies doivent être soumis au rédacteur-en-chef.

Présentation générale: Le manuscript doit comprendre le collage. Dimensions des pages, $8.5^{\prime \prime} \times 11 "$. Si vous avez accès à un système de traitement de texte, dans la mesure du possible, suivre le format des articles dans l'Acoustique Canadienne 18(4) 1990. Tout le texte doit être en caractères Times-Roman, $10 \mathrm{pt}$ et à simple (12 pt) interligne. Le texte principal doit être en deux colonnes séparées d'un espace de 0.25 ". Les paragraphes sont séparés d'un espace d'une ligne.

Marges: Dans le haut - page titre, 1.25"; autres pages, 0.75"; dans le bas, $1 "$ minimum; latérales, $0.75^{\prime \prime}$.

Titre du manuscrit: 14 pt à 14 pt interligne, lettres majuscules, caractères gras. Centré.

Auteurs/adresses: Noms et adresses postales. Lettres majuscules et minuscules, 10 pt à simple (12 pt) interligne. Centré. Les noms doivent être en caractères gras.

Sommaire: En versions anglaise et française. Tiłre en $12 \mathrm{pt}$, lettres majuscules, caractères gras, centré. Paragraphe 0.5" en alinéa de la marge, des 2 cotés.

Titres des sections: Tous en caractères gras, 12 pt, TimęsRoman. Premiers titres: numéroter $1,2,3, \ldots$, en lettres majuscules; sous-titres: numéroter $1.1,1.2,1.3, \ldots$, en lettres majuscules et minuscules; sous-sous-titres: ne pas numéroter, en lettres majuscules et minuscules et soulignés.

Equations: Les minimiser. Les insérer dans le texte si elles sont courtes. Les numéroter.

Figures/Tableaux: De petites tailles. Les insérer dans le texte dans le haut ou dans le bas de la page. Les nommer "Figure 1, 2, 3,.." Légende en 9 pt à simple (12 pt) interligne. Laisser un espace de 0.5 " entre le texte.

Photographies: Soumettre la photographie originale sur papier glacé, noir et blanc.

Références: Les citer dans le texte et en faire la liste à la fin du document, en format uniforme, 9 pt à simple (12 pt) interligne.

Pagination: Au crayon pâle, au bas de chaque page.

Tirés-à-part: Ils peuvent être commandés au moment de l'acceptation du manuscrit. 


\section{Choice. Convenience. Cost. No one else compares.}
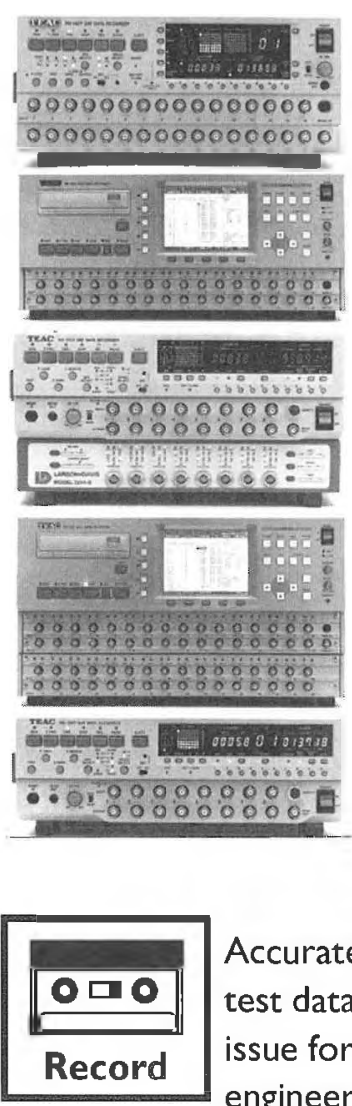

Accurately recording test data is a critical issue for every test engineer. You only

get one shot, because repeats are expensive, if not impossible. That's a fact we understand. That's why TEAC offers more combinations of affordable recorders, data analysis programs and downloading options than anyone else. For digital recording we have seven different compact, portable DAT models with extended dynamic range and high signal-to-noise ratios.
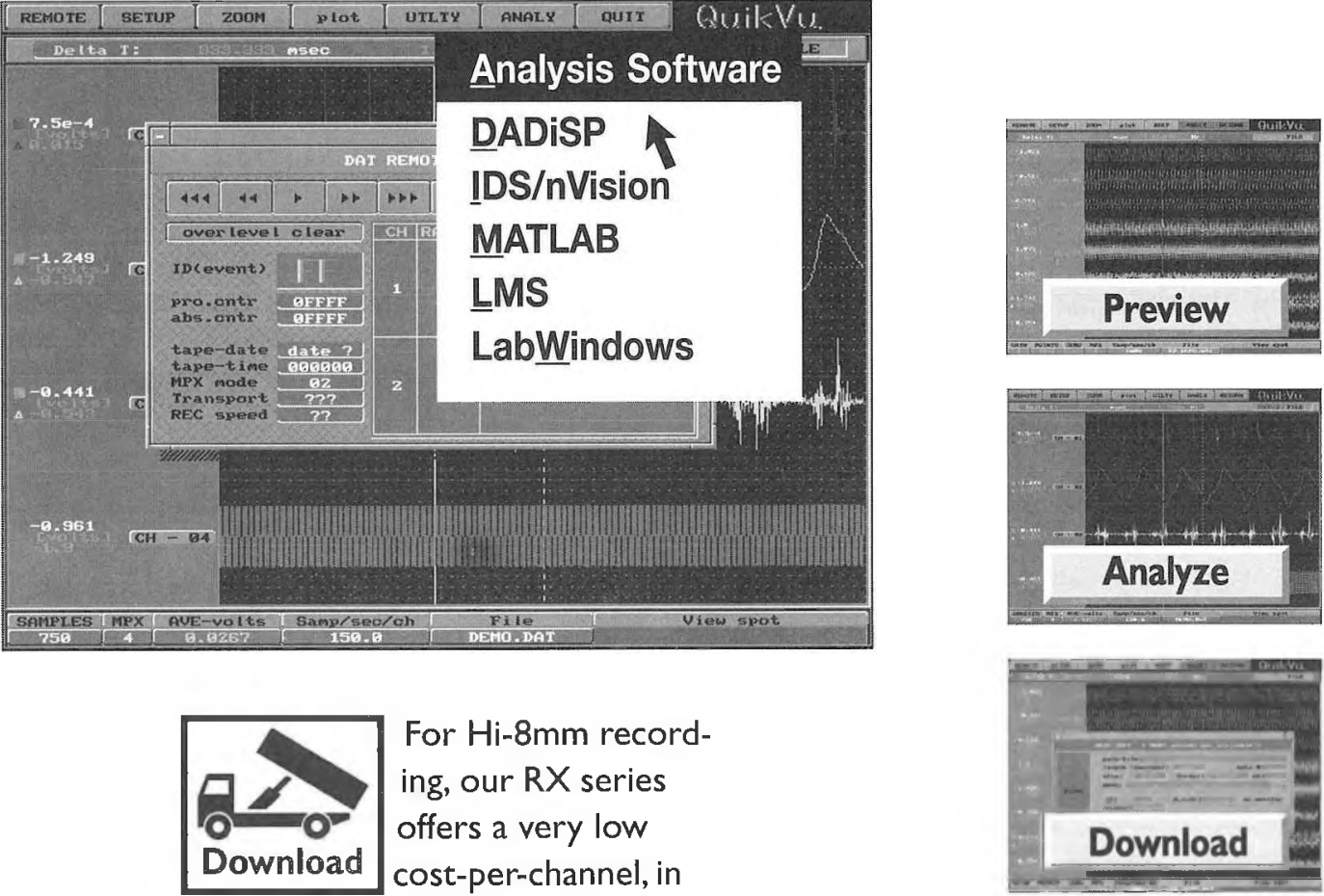

For $\mathrm{Hi}-8 \mathrm{~mm}$ recording, our RX series offers a very low cost-per-channel, in either a 16 or 32 channel model. Using multiple units, you can synchronously record up to 128 channels. These units feature $\mathrm{S} / \mathrm{N}$ ratios greater than $80 \mathrm{~dB}$, a $20 \mathrm{kHz}$ bandwidth and up to 60 minutes of record time. And using on-board, menu-driven programming, you can easily record up to $7 \mathrm{~GB}$ of data.

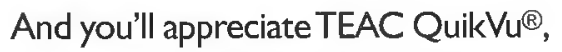
a real-time $\mathrm{PC}$ or PCMCIA software program that lets you preview test data before you record. It allows you to monitor data in real time as well as archive or transfer data to other systems. And speaking of software, TEAC offers another major advantage.
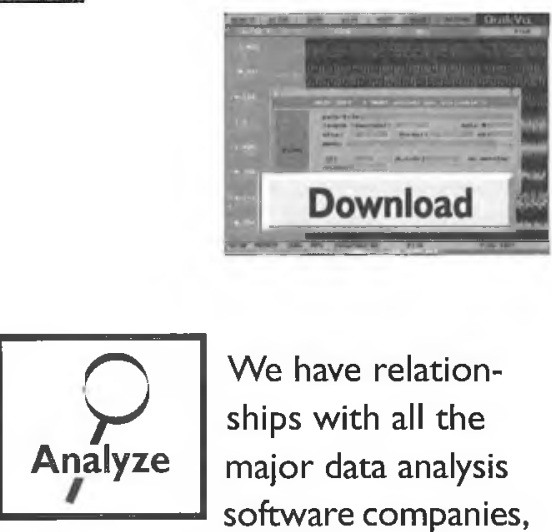
so our recorders are compatible with their programs. That makes your data analysis much easier ... much faster. Just pick your favorite analytical program and go to work.

Choice. Convenience. Cost.

We're the only one who can give you a total solution for virtually any application. In fact, if we don't have it, you probably don't need it.

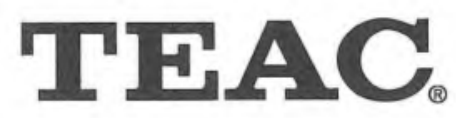

INSTRUMENTATION DATA RECORDERS
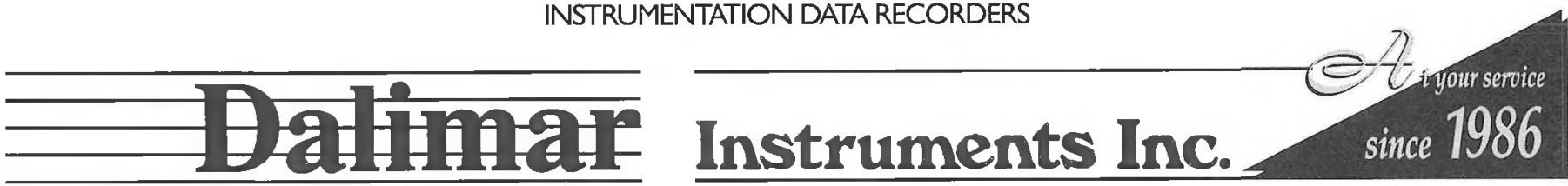

193, Joseph Carrier, Vaudreuil-Dorion, Quebec, Canada J7V 5V5 Tel.: (450) 424-0033 Fax: (450) 424-0030 90 "C" Centurian Drive, Suite 206, Markham, Ontario, Canada L3R 8C5 Tel.: (905) 948-8345 Fax: (905) 948-8344 


\section{SYSTEM 824}

\section{Five sophisticated acoustical instruments in One!}

Integrating Sound Level Meter meeting Type 1

- Standards with simultaneous measurement of sound pressure levels using fast, slow, and impulse detector, and simultaneous $\mathrm{A}, \mathrm{C}$, and flat weighting. It measures 48 sound pressure parameters at once! All this with a $105 \mathrm{~dB}$ linearity range!

Simple Sound Analyzer with simultaneous sound pressure level measurement and real-time $1 / 3$ octave frequency analysis.

Logging Sound Level Meter permits data gathering of broadband sound pressure levels and frequency spectra over user-defined time intervals.

Real Time Frequency Analyzer with $1 / 1$ and $1 / 3$ octave analysis over a $20 \mathrm{kHz}$ frequency range and optimized for characterizing steady-state or high speed transient events.

Fast Fourier Transform Analyzer with 100, 200, and

5400 lines resolution and $20 \mathrm{kHz}$ range for specific frequency investigations.

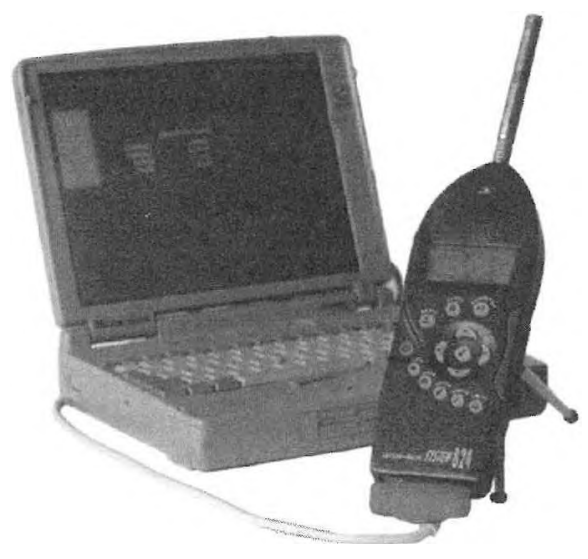

Listen Nhn with Larson•Davis

\section{L}
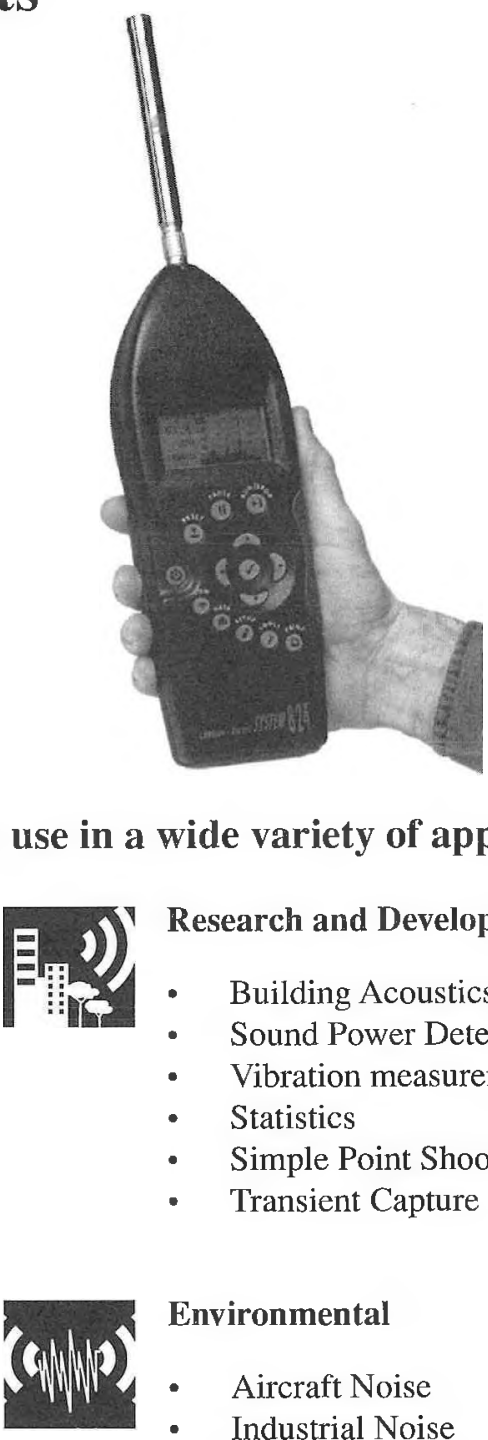

For use in a wide variety of applications

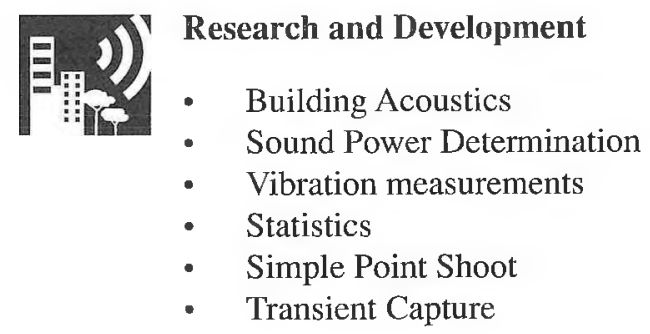

Environmental

- Aircraft Noise

- Industrial Noise

- General Surveys

- Transportation Noise

- Community Noise

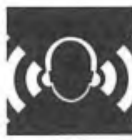

\section{Worker Safety}

- Noise Exposure Measurements

- Work Place Surveys

- Machinery Noise

- Audiometric Calibration

- Simultaneous C minus A Measurements 